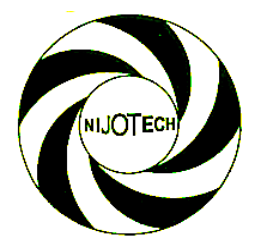

Nigerian Journal of Technology (NIJOTECH)

Vol. 35, No. 3, July 2016, pp. $642-646$

Copyright@ Faculty of Engineering, University of Nigeria, Nsukka,

Print ISSN: 0331-8443, Electronic ISSN: 2467-8821

www.nijotech.com

http://dx.doi.org/10.4314/njt.v35i3.24

\title{
TEMPERATURE FLUCTUATION INSIDE INERT ATMOSPHERE SILOS
}

\author{
E. S. Ajayi ${ }^{1,2, *}$, M. A Omodara², S. N. Oyewole ${ }^{3}$, A. R. Ade ${ }^{4}$ and F. A Babarinsa ${ }^{5}$

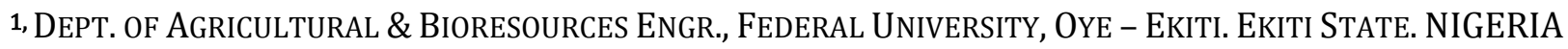 \\ 2, 3,4,5 Nigerian Stored Products RESEARCH InSTITUTE, KM 3, ASA-DAm RoAd, ILORIN. KWARA STATE. NiGERIA \\ E-mail addresses:1 emmanuel.ajayi@fuoye.edu.ng, 2 omodarama@nspri-ng.org,3snoyeengr@gmail.com, \\ 4adeayokanmi@gmail.com, 5 fababarinsa@yahoo.com
}

\begin{abstract}
This research was conducted to study temperature fluctuation inside the inert atmosphere silos loaded with wheat, compare the temperature fluctuation across the top, middle and bottom part of the silo in relation to the ambient temperature. Temperature readings of the ambient and at the top, middle and bottom part of the two silos for twenty-eight (28) months of storage were recorded in order to monitor temperature fluctuation at different sections inside the inert atmosphere silos loaded with two varieties of wheat namely LACRIWHT-2 (Cettia) and LACRIWHT-4 (Atilla-Gan-Atilla) from Lake Chad Research Institute, Maiduguri, Nigeria. Statistical Analysis System (SAS) software was used to run analysis of variance and $t$-Test on the data. The findings revealed that there is significant difference in the mean temperature at different position or sections of the silos and as well between the two silos. The mean temperatures at the top, middle and the bottom of the inert atmosphere silos were approximately $29.35^{\circ} \mathrm{C}, 28.19{ }^{\circ} \mathrm{C}$ and $26.51^{\circ} \mathrm{C}$ respectively. Temperatures decreases from the top of grain bulk towards the floor of the inert atmosphere silos.
\end{abstract}

Keywords: Temperature, inert atmosphere, silo, structure, storage.

\section{INTRODUCTION}

Inert Atmosphere Storage technology essentially involves the displacement of the interstitial atmosphere of stored bulk by the injection of an inert gas until the residual oxygen content is reduced to almost $0 \%$. The preference of nitrogen to other inert gases most especially carbondioxide $\left(\mathrm{CO}_{2}\right)$ is due to safety of nitrogen $\left(\mathrm{N}_{2}\right)$ to the environment, operators and consumers, residue free application and relatively low cost and more importantly, nitrogen makes up about $78 \%$ normal air, this makes it users' and environmental friendly and has proved to be a suitable option for pest and quality control when storing grains in metal silos [1]. The increasing evidence of the hazards that traditional pesticides pose to human health, the environment, wild life, and even to agriculture and resistance of pests to some long-standing pesticides have led to international objection to the use of toxic chemicals in food storage. The control atmosphere has proved to be a better alternative to the use of toxic chemicals because of its minimal adverse effect on either the commodity or the environment since the constituents are present normally in the storage atmosphere and in the environment [2].

The use of inert atmosphere silos in Nigeria dated back to 1980. Although, the application of control atmosphere silos in Nigeria has proven to be effective in the control of stored products pest of grains especially, cowpea weevil which has been a major challenge for farmers in the North, it has not been widely reported. This is due largely to the fact that the first set of silos were designed and constructed by foreigners and involves the use of sophisticated gadgets that cannot be easily adopted by farmer [3].

The factors affecting temperature of grains in store includes the bin or silo size, wall insulation, shading of the bin or silo complex, heat generation by the grain and the surrounding, material of construction and grain agitation. Temperature differential is higher in small bin than big bin because of the distance from the wall to the centre of the bin is small. During winter, small bin also cools faster than the big bin. In large bin, the bulk of weight of grains acts as an insulation which adds to the overall insulation. Silo should be made of materials with good insulating properties and

${ }^{*}$ Corresponding author Tel: +234-803-915-2430 
also resist heat flow from solar radiation from outside. This is usually achieved by painting the silo wall with white paint.

Some of the advantages of inert atmosphere storage as reported by [2] includes: it has the potential to kill all animals including insect (all stages), mites, rodents, and birds without the use of toxic chemicals; it inhibits the growth of microorganisms, particularly aerobic fungi, thereby reducing the production of mycotoxins; toxic chemicals are excluded, thereby eliminating hazards to operators and toxic chemical residues on crops; it reduces grain respiration; it reduces oxidative degradation; and by nature of the structures used generally in control atmosphere storage, protection is offered against external re-infestation from insects, rodents, and birds; there is little chance of development of resistance to low-oxygen control atmosphere. However, it has its own limitations or disadvantages which include: slow process of disinfestations as compared with fumigation; high level of air tightness is required for successful storage; there is inadequate information about its reliability as a technology for crop storage, especially in the developing countries. According to [4], some of the technical and non-technical barriers that limit wider adoption fumigation or control atmosphere in sealed storages in most States of Australia includes: resistance by manufacturers to changes in manufacturing methods and designs, poor understanding of sealing technology by manufacturers, wide range of contact insecticides registered for on-farm use, existing market for premium-priced residue-free commodities is limited in size, growers unwilling to invest capital to seal existing storages or purchase new units, lack of widely available extension information targeted at growers, traders and manufacturers of grain storage and management equipment, limited funds to promote grain management practices and deregulated grain industry which encourages holding of grains on farms under variable quality storage conditions. Silos are the most appropriate modern structures for the bulk storage of grains; their performances are greatly influenced by the materials of construction and the climatic environment where they are used. Under the warm and humid environment prevalent in Nigeria, these silos of temperate region origin, although purchased and stocked at very high costs, experience moisture condensation, hot spot development, high temperature fluctuation and caking which results into grain deterioration [5]. The objectives of the research are therefore to study the temperature fluctuation inside the inert atmosphere silos loaded with wheat, compare the temperature fluctuation across the top, middle and bottom part of the silo in relation to the ambient temperature and between the two varieties of wheat stored in two different silos located on the same foundation.

\section{MATERIALS AND METHODS}

\subsection{Study Area}

The study was conducted at the headquarters of Nigerian Stored Products Research Institute, Ilorin, Nigeria. Ilorin, the capital city of Kwara State is located between latitudes $11^{\circ} 2^{\prime}$ and $4{ }^{\circ} 51^{\prime} \mathrm{N}$ and longitudes $2^{\circ} 45^{\prime}$ and $6^{\circ} 40^{\prime} \mathrm{E}$ at an altitude of about $375 \mathrm{~m}$. The natural climate is characterized by both the wet and dry seasons with the rainy season beginning towards the end of April and lasting till October while the dry season begins in November and ends in March. Days are very hot during the dry season with November to January temperatures rising up to $34^{\circ} \mathrm{C}$, while from February to April, the temperature further increases to between $34.6^{\circ} \mathrm{C}$ and $37^{\circ} \mathrm{C}$. The total annual rainfall in Ilorin is about $1318 \mathrm{~mm}$. The relative humidity in the wet season is between $75 \%$ and $80 \%$ while in the dry season, it is about $65 \%$ [6].

\subsection{Description of the Silos}

The Silos consist of two units of 50 tons inert atmosphere silos located at the headquarters of Nigerian Stored Products Research Institute, Ilorin, Nigeria. The geometry of the silo is as follows:

Diameter of the cylinder and cone $=4 \mathrm{~m}$

Height of the cylinder $\quad=5.4 \mathrm{~m}$

Total height of silo $\quad=6.4 \mathrm{~m}$

Based on the geometry of the silo structure, the dimension of the cellular raft foundation base is as follows:

$\begin{array}{ll}\text { Total width } & =12 \mathrm{~m} \\ \text { Total breadth } & =6 \mathrm{~m} \text { with } \\ \text { Top slab thickness } & =300 \mathrm{~mm} \\ \text { Width of the beam } & =600 \mathrm{~mm} \\ \text { Height of the beam } & =1000 \mathrm{~mm} \\ \text { Bottom raft thickness } & =400 \mathrm{~mm} .\end{array}$

The inert atmosphere silo is as shown in Figure 1.

\subsection{Air-tightness of the Structure}

Testing of sealing effectiveness was done using the method of pressure-decay testing procedures as recommended by CSIRO Australia. A pressure differential between the inside and outside of the storage enclosure was applied by applying a pressure of $250 \mathrm{~Pa}$ to the silos and the time taken for the 
pressure to drop to about half was 4 minutes 44 seconds which is less than the recommended pressure decay of one half of an induced pressure of 5 minutes. The result of the air-tightness test indicated that the silos were 'air tight'.

\subsection{Materials Stored inside the Silos}

The two varieties of wheat stored inside the inert atmosphere silos are LACRIWHT-2 (Cettia) and LACRIWHT-4 (Atilla-Gan-Atilla) from Lake Chad Research Institute, Maiduguri, Nigeria. LACRIWHT-4 (Atilla-Gan-Atilla) was stored in Silo A while LACRIWHT-2 (Cettia) was stored in Silo B.

\subsection{Data Collection.}

Temperature and relative humidity readings were taken thrice daily from the sensors as shown in Figure 1 for the period of twenty eight months. While temperature and relative humidity of the ambient were taken for the entire period, it was only the temperatures inside the silos that were taken at the top, middle and the bottom of the silos.

\subsection{Data Analysis}

Descriptive and Inferential Statistics were used to analyse the data gathered during the experiment. The descriptive statistics used was mainly the mean to determine the average monthly temperature over the period. Statistical Analysis System (SAS) software was used to run analysis of variance (ANOVA) and t-test to determine variations and also compare different means within and between the two structures.

\section{RESULTS AND DISCUSSION}

\subsection{Results}

Temperature readings of the ambient and at the top, middle and bottom part of the two silos for twentyeight (28) months of storage were presented in Figure 2 and Figure 3. The ambient relative humidity varies from $54 \%$ around January to $90 \%$ around August and September. The result of Analysis of Variance (ANOVA) and t-test analyses are presented in Table 1 and Table 2 respectively.

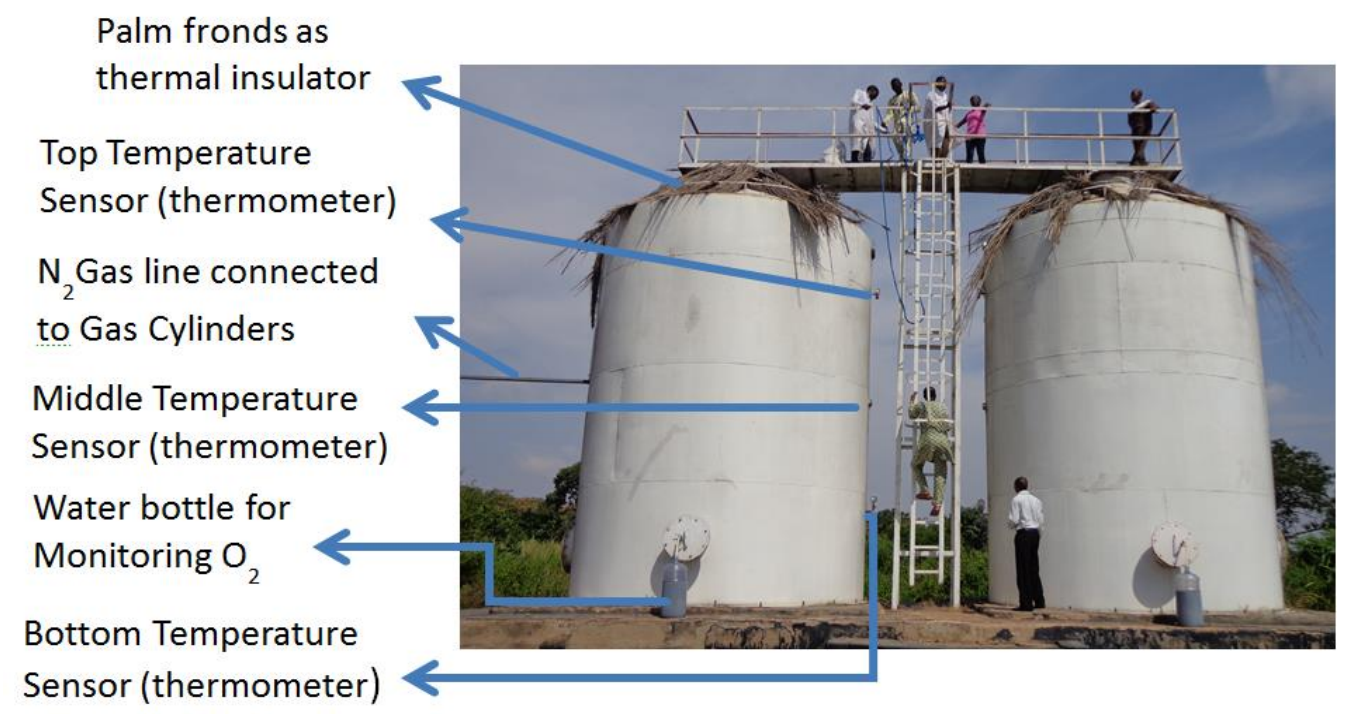

Figure 1. A 2-unit fifty (50) tonnage inert atmosphere silos at NSPRI

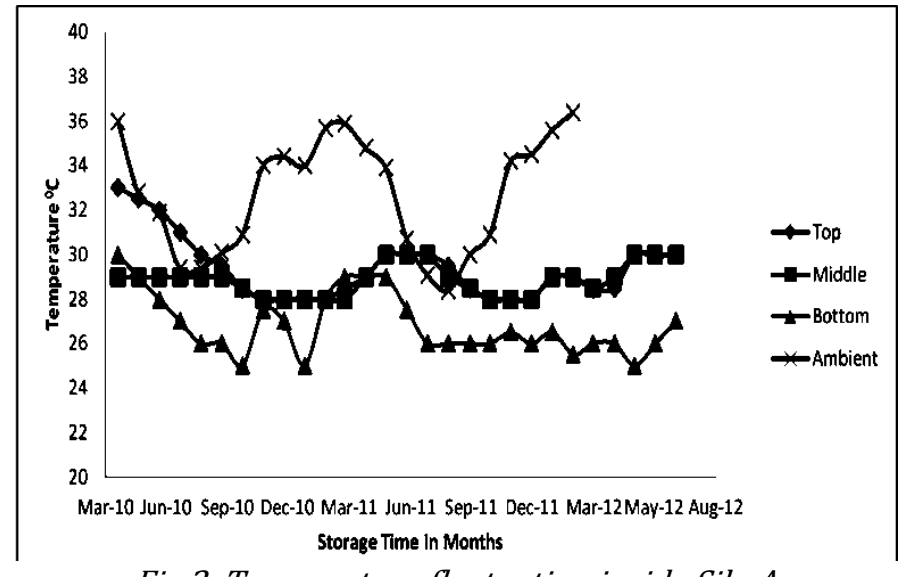

Fig.2: Temperature fluctuation inside Silo A

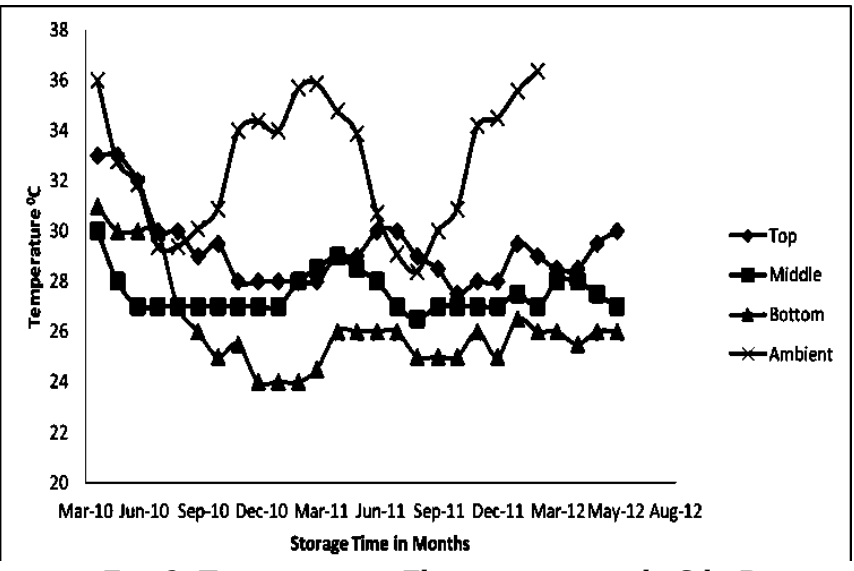

Fig. 3: Temperature Fluctuation inside Silo B 
Table 1: Analysis of Variance (ANOVA)

\begin{tabular}{lrrrrr}
\hline Source & DF & Type III SS & Mean Square & F Value & Pr $>$ F \\
\hline Position & 2 & 228.2261905 & 114.1130952 & 142.91 & $<.0001$ \\
Silo & 1 & 20.3705357 & 20.3705357 & 25.51 & $<.0001$ \\
Period & 27 & 166.9211310 & 6.1822641 & 7.74 & $<.0001$ \\
Silo*Position & 2 & 10.9642857 & 5.4821429 & 6.87 & 0.0022 \\
Period*Position & 54 & 61.1904762 & 1.1331570 & 1.42 & 0.1008 \\
Silo*Period & 27 & 12.9211310 & 0.4785604 & 0.60 & 0.9251 \\
\hline
\end{tabular}

Table 2: t-Test (Least Significant Difference) for Comparison of Means.

\begin{tabular}{|c|c|c|c|c|c|c|}
\hline & Means & $\mathrm{N}$ & $\begin{array}{l}\text { Error Mean } \\
\text { Square }\end{array}$ & $\begin{array}{c}\text { Critical Value } \\
\text { of } t\end{array}$ & $\begin{array}{l}\text { Error Degree of } \\
\text { Freedom }\end{array}$ & $\begin{array}{l}\text { Least Significant } \\
\text { Difference }\end{array}$ \\
\hline \multicolumn{7}{|c|}{ Position } \\
\hline 1 & 29.3482 & 56 & \multirow{3}{*}{0.798501} & & \multirow{3}{*}{54} & \multirow{3}{*}{0.3386} \\
\hline 2 & 28.1875 & 56 & & 2.00488 & & \\
\hline 3 & 26.5089 & 56 & & & & \\
\hline \multicolumn{7}{|c|}{ Silo } \\
\hline A & 28.3631 & 84 & \multirow{2}{*}{0.798501} & & \multirow{2}{*}{54} & \multirow{2}{*}{0.2764} \\
\hline $\mathrm{B}$ & 27.6667 & 84 & & 2.00488 & & \\
\hline
\end{tabular}

Note: Position 1, 2, 3 means top, middle and bottom of the silos and alpha $=0.05$

$(1-2)>$ LSD means there is significant difference between the means.

$(1-3)>$ LSD means there is significant difference between the means

$(2-3)>$ LSD means there is significant difference between the means

(A-B) $>$ LSD means there is significant difference between the means.

\subsection{Discussion}

The temperatures in the silo taken at the top, middle and the bottom through the installed temperature gauges or sensors are shown in Figure 1 and 2 for silos $\mathrm{A}$ and $\mathrm{B}$ respectively. The results show that the highest value of $33{ }^{\circ} \mathrm{C}$ was recorded in April 2010 (which marks the start of the storage period inside the inert atmosphere silos) for the top part of the two silos. This might be due to heat built up due to the activities of insects in the first month of storage. The temperature reached the minimum value of $28{ }^{\circ} \mathrm{C}$ at the top and middle of silo A after about 210 days (November 2010) of storage inside the inert atmosphere while the temperature reached the minimum value of $27.5{ }^{\circ} \mathrm{C}$ at the top and $26.5^{\circ} \mathrm{C}$ at the middle in October 2011 and August 2011 respectively for the top and middle part of silo B. The temperature drop was higher at the bottom for both silos. In Silo A, temperature dropped to the lowest value of $25{ }^{\circ} \mathrm{C}$ in October 2010 (after about 180 days of storage) while in Silo B it dropped to $24{ }^{\circ} \mathrm{C}$ in December 2010 (after about 240 days of storage). As shown in Figure 1 and Figure 2, temperatures were relatively steady in the middle part of both silos. At the initial stage, the temperatures at the bottom were higher than at the middle while the temperatures at the top section were higher initially and later dropped to almost the same level at the middle in Silo A. Although temperatures inside Silo B seemed lower compared to Silo A, there was more fluctuation in temperatures inside Silo B than Silo A. This could be attributed to the position of the silo relative to the sun and probably due to varietal difference between the wheat stored in both silos. The investigation did not cover the effect of varietal difference on temperature fluctuation inside the structures.

According to Table 1, the position (top, middle and bottom sections) of the silo, difference in silos (Silo A or Silo B) and the period (in months) of storage were all significant at $P<0.0001$. Also, the combined effect of the position and the difference in silos was significant at $P$ equals to $0.0022(P=0.22 \%)$. This fact is supported by Table 2 which shows that there is significant difference in the mean temperature at different position or sections of the silos and as well between the two silos. This implies that the temperature fluctuations or the variations in the means depend on the position inside the silo, the period and which silo was used to store the wheat. Meanwhile, the combined effect of the period and the 
position inside the silo and, the silo used and the period of storage were significant at $P$ equals to 0.1008 and 0.9251 respectively. This implies that any difference observed due to any of these effects is due only to random variation. Temperatures decreases from the top of grain bulk towards the floor of the inert atmosphere silos. This observation is in agreement with [7] and [8] who reported that the temperature within silo enclosure increases with height, the highest temperature was recorded in the point nearest to the roof, which is an indication that heat penetrates into the silo through the roof. This effect was drastically reduced by the shade provided by palm fronds used to cover the roof part of both silos. However, the temperatures within the inert atmosphere silos at all the different sections (top, middle and bottom) were generally lower than the ambient temperatures except for the months of June, July and August with high ambient relative humidity (wet season) when the temperature of only the top part of the silo exceeded the ambient temperature (as shown in Figure 2 and Figure 3). This shows a great potential of the inert atmosphere storage technology in reducing the effect of the ambient temperatures on the temperature inside the silo.

\section{CONCLUSION}

This study established the fact that the temperature within inert atmosphere silo increases with height. The mean temperatures at the top, middle and the bottom of the inert atmosphere silos were approximately $29.35^{\circ} \mathrm{C}, \quad 28.19^{\circ} \mathrm{C}$ and $26.51^{\circ} \mathrm{C}$ respectively. Temperatures decreases from the top of grain bulk towards the floor of the inert atmosphere silos. However, it demonstrated that temperature fluctuation which is a major cause of moisture condensation in conventional metal silos is relatively low in inert atmosphere silos thus prevent spoilage due to caking. This indicates the great potential of the inert atmosphere storage technology in reducing the effect of the ambient temperatures on the temperature inside the silo. Based on the findings of this study it is recommended that further study should look into modelling of gas consumption pattern in inert atmosphere silos, effect of varietal differences on temperature fluctuation and improved insulation for inert atmosphere silos.

\section{ACKNOWLEDGEMENT}

The authors wish to appreciate all the Technical Staff in the Postharvest Products Engineering Research
Department of Nigerian Stored Products Research Institute most especially the Laboratory Technologists namely: Mr. Andrew Adeiza, Mrs. O. C. Ogunjirin, Mr. M. O. Ojekunle and Mrs. F. M. Omopariola for their immeasurable contribution towards the success of this study. We also express our gratitude to the Management of the Institute for the confidence they have in the institute's team of engineers to design and construct the first sets of indigenous inert atmosphere silos in Nigeria. We appreciate the effort Dr Adewale Daniel of the Department of Crop Science and Horticulture, Federal university, Oye - Ekiti for the statistical analysis.

\section{REFERENCES}

[1] Babarinsa, F. A. Silo Construction, Maintenance and Usage. Nigerian Stored Products Research Institute (NSPRI) Research News. Number 1,ISSN 0794-6414, 2011.

[2] Agboola, S. D. Current Status of Controlled Atmosphere Storage in Nigeria. Journal of Food Technology in Africa. Vol. 6, Number 1, 2001, pp 30 36 ,

[3] Adesuyi S. A., Shejbal J, Oyediran J.O, Kuku, F.O, Sowunmi, O, Akinnusi, 0, Onayemi, 0. Application of artificial control atmospheres to grain storage in the tropics: Case Study in Nigeria. In: Shejbal, J. (Ed), Controlled Atmosphere Storage of Grains. Elsevier Scientific Publishing Company, Amsterdam, 1980, pp. 259 - 279.

[4] Andrews, A. S., Annis, P. C. and Newman, C. R. Sealed storage technology on Australian farms. In Proceedings of the $6^{\text {th }}$ International Working Conference on Stored-Product Protection Canberra, Australia. Vol. 1, 1994, Pp. 27 - 36.

[5] Yahaya Mijinyawa, E. B Lucas, F. O. Adegunloye. Termite Mound Clay as Material for Grain Silo Construction. Agricultural Engineering International: the CIGRE Journal. Manuscript BC 07 002. Vol. IX. July, 2007.

[6] Tinuoye, A. Climatic condition in dry and wet years at Ilorin. Unpublished B.SC dissertation, Department of Geography University of Ilorin, Nigeria, 1990.

[7] Alabadan B. A. Temperature Changes in Bulk Stored Maize. AU J. T. Vol. 9, Number 3, 2006,pp 187 - 192.

[8] Adejumo B. A. Development of a 350kg DoubleWalled Insulated Metallic Silo for Tropical Climate. Greener Journal of Science, Engineering and Technology Research. Vol. 3, Number 6, 2013, pp 195-204. 